\title{
Carinal resection and reconstruction: now and in the future
}

\author{
Natsumi Matsuura, Hitoshi Igai, Mitsuhiro Kamiyoshihara \\ Department of General Thoracic Surgery, Japanese Red Cross Maebashi Hospital, Maebashi, Japan \\ Correspondence to: Natsumi Matsuura, MD, PhD. Department of General Thoracic Surgery, Japanese Red Cross Maebashi Hospital, 389-1 Asakura, \\ Maebashi 371-0811, Japan. Email: nmori1130@gmail.com. \\ Comment on: Chen J, Ang KL, Wang C, et al. Minimally invasive carinal reconstruction using bronchial flap and omental flap reinforcement. Ann \\ Thorac Surg 2021. [Epub ahead of print]. doi:10.1016/j.athoracsur.2021.06.014.
}

Submitted Sep 06, 2021. Accepted for publication Sep 18, 2021.

doi: $10.21037 /$ tlcr-21-731

View this article at: https://dx.doi.org/10.21037/tlcr-21-731

Even today, one of the most technically challenging surgical procedures for thoracic surgeons is carinal resection and reconstruction. This surgery is mainly performed for neoplasms that affect the distal trachea and the carina. Carinal tumors, as a subcategory of tracheal tumors, are even less common. With the decrease in squamous cell carcinoma resulting from the declining smoking rate, the frequency of central airway tumors is further decreasing. Therefore, carinal resection is one of the operations that is very difficult to standardize. There is a limit to the cartilage rings that can be excised, cartilage healing is poor, and there are intraoperative respiratory management problems, such as the need for intubation of the surgical field.

In recent years, the morbidity and mortality have decreased by advances in anesthesia technique, improved intensive care, and strict surgical indications based on detailed preoperative examination. In intraoperative anesthesia management, high inspiratory oxygen concentrations, multiple collapses and re-expansions, hypoxic pulmonary vasoconstriction and hypoperfusion of the ipsilateral lung, and fluid overload must be avoided (1). Some ideas regarding respiratory management during carinal resection and anastomosis have also been reported. Macchiarini et al. reported the apneic (hyper) oxygenation technique, in which patients are preoxygenated and hyperventilated with $100 \%$ oxygen for about $10 \mathrm{~min}$ before completing the dissection and are then completely apneic. During the anastomosis, hyperoxygenation is initiated by placing a small catheter across the surgical field into the contralateral main bronchus and connecting it to a sterile line delivering 10 to $15 \mathrm{~L} / \mathrm{min}$ $\mathrm{O}_{2}$ continuously under minimal breathing pressure $(0$ to $1 \mathrm{mmHg}$ ) (2). Table 1 shows some of the main reports of carinal resection for the last 30 years (2-8). Carinal resection is more frequently associated with pulmonary resection such as right or left pneumonectomy, but the method of carinal reconstruction differs greatly depending on whether it is

Table 1 Summary of recent reports of carinal resection with lobectomy or without lung resection

\begin{tabular}{|c|c|c|c|c|}
\hline Author & Time period & $\begin{array}{l}\text { Carinal resection with lobectomy or without lung } \\
\text { resection }(n)\end{array}$ & Morbidity & Mortality \\
\hline Macchiarini et al. & 1999-2003 & 16 & 10 (63\%) & $1(6 \%)$ \\
\hline Porhanov et al. & 1979-2001 & 40 & 12 (30\%) & $3(7.5 \%)$ \\
\hline Mitchell et al. & 1973-1998 & 23 & $10(43 \%)$ & $2(8.7 \%)$ \\
\hline Yamamoto et al. & 1989-1999 & 14 & $7(50 \%)$ & $1(7.1 \%)$ \\
\hline Costantino et al. & 1997-2017 & 22 & $26(58 \%)^{\star}$ & $0(0)$ \\
\hline
\end{tabular}

${ }^{*}$, including carinal pneumonectomy cases. 
accompanied by pneumonectomy, and the postoperative course is also different. Since most reports include carinal pneumonectomy, only those with carinal resection with lobectomy or without lung resection were extracted. In these series, the morbidity rate was still relatively high, but the mortality rate was acceptable. These series indicated that induction chemotherapy and the presence of mediastinal lymph nodes metastasis (N2) were associated with increased risk of complications.

Although carinal resection often requires right or left pneumonectomy, lung parenchyma must be preserved as much as possible if oncologically acceptable and anatomically possible. Various methods for carinal reconstruction have been reported, including: doublebarrel method; end-to-end left main bronchus with trachea and end-to-side bronchus intermedius to trachea; endto-end left main bronchus with trachea and end-to-side bronchus intermedius to left main bronchus; and endto-end right main bronchus with trachea and end-toside left main bronchus to right main bronchus (1-8). Yamamoto et al. also reported an alternative technique (7). After the tracheal carina is resected, two thirds of the circumference of the trachea and the left main bronchus are anastomosed and after trimming the remaining one third of the circumference, the right bronchus is anastomosed to this trimmed orifice in end-to-side fashion. In either case, the most important thing is to reduce tension on the anastomotic site and maintain sufficient blood flow. Especially when anastomosing the bronchus to the side of trachea, it is necessary to raise the residual lung considerably to the cranial side. The release maneuvers (e.g., inferior pulmonary ligament release, inferior U-shaped hilar release, pericardiophrenic release) are mandatory (1).

These surgeries have been performed with mainly through a right posterolateral thoracotomy or a median sternotomy. However, the rise of minimally invasive surgery in recent years has made it possible to perform these surgeries also under thoracoscopic or robotic-assisted surgery, although there have been only small series in limited institutions. Video-assisted thoracoscopic surgery (VATS) has proven to be safe and effective and recognized as a standard procedure for lung resection, but the use of VATS for extended surgery such as tracheal, bronchial, and carinal procedures and angioplasty remains limited (9-12). However, reducing postoperative pain and less damage to the respiratory muscles would help with early recovery, fewer postoperative complications, and shortening the length of the postoperative hospital stay. Li et al. reported
VATS resection and reconstruction of the carina and trachea for malignant or benign disease in 12 patients (11). Of these 12 cases, they performed right main bronchus resection and carinal reconstruction in 2 , right main bronchus resection and partial carinal resection in 3 , and left main bronchus resection and carinal reconstruction in 1 . In those series, no in-hospital mortality or major morbidity occurred. In this report, several key issues were described. Since all anastomoses in these series were performed by single continuous suture, matching of anastomosis orifices between the bronchial opening and the tracheal or carinal opening after resection was important. They used the Aortic Punch (Medtronic, Inc., Minneapolis, MN, USA) to enlarge the orifices. They also reported thoracoscopic surgery for tracheal and carinal resection and reconstruction under spontaneous ventilation (12). In this series, they performed four carinal resections and reconstructions without intubation. Patients were anesthetized using intravenous anesthesia (propofol, remifentanil and sufentanil), they were allowed to breathe spontaneously, and no muscle relaxant was used. A laryngeal mask was used to assist airway management. They demonstrated that without the endotracheal tube, the trachea is more flexible, with a wider range of motion during resection and anastomosis. Moreover, it gives surgeons the advantage of an unobstructed view of the surgical field and can improve the anastomosis and operating times.

Whereas multiport VATS is mainstream, uniportal VATS (U-VATS) has emerged as a minimally invasive procedure with less postoperative pain. Gonzalez-Rivas reported anatomical lung resection, and it has developed to more complex surgery, such as segmentectomy and sleeve resection (13-15). Gonzalez-Rivas et al. recently reported 5 cases of U-VATS lung-sparing tracheal-bronchial and carinal sleeve resections (16). In U-VATS, the camera is always at the posterior side of the incision with the same angle as the operator's viewpoint, providing a similar view to open surgery. Moreover, the use of forceps and energy devices designed and developed for U-VATS enabled the operator to carry out dissection effectively. In airway management, they used a jet ventilation catheter that permits unobstructed visualization and manipulation of the stumps during the reconstruction.

In recent years, robotic-assisted thoracoscopic resection and reconstruction of the carina have also been reported $(17,18)$. Since the first reported use of the da Vinci robotic system for thoracic surgery in 2002 (19), the application of robotic surgical techniques has become increasingly 
widespread. Li et al. demonstrated that with the robotic arm's extra maneuverability, anastomosis suturing was relatively easier than with the VATS approach, and 3D visualization also enhanced the procedure's accuracy compared with VATS, the routine 2D display (18). Currently, there are only a few case reports, but it is necessary to accumulate cases and verify the role of robotassisted thoracoscopic surgery (RATS) in the future.

In conclusion, carinal resection and reconstruction are rarely performed. Strict surgical indications, cooperation with anesthesiologists, dedicated postoperative care, and technical expertise in high-volume centers are needed. Minimally invasive surgery has been reported in this area, whether VATS or RATS, and it will take some time before it becomes generally widespread. However, given the characteristics of RATS (e.g., excellent three-dimensional vision with magnification, articulating instruments), it may replace thoracotomy in the future.

\section{Acknowledgments}

Funding: None.

\section{Footnote}

Provenance and Peer Review: This article was commissioned by the editorial office, Translational Lung Cancer Research. The article did not undergo external peer review.

Conflicts of Interest: All authors have completed the ICMJE uniform disclosure form (available at https://dx.doi. org/10.21037/tlcr-21-731). The authors have no conflicts of interest to declare.

Ethical Statement: The authors are accountable for all aspects of the work in ensuring that questions related to the accuracy or integrity of any part of the work are appropriately investigated and resolved.

Open Access Statement: This is an Open Access article distributed in accordance with the Creative Commons Attribution-NonCommercial-NoDerivs 4.0 International License (CC BY-NC-ND 4.0), which permits the noncommercial replication and distribution of the article with the strict proviso that no changes or edits are made and the original work is properly cited (including links to both the formal publication through the relevant DOI and the license). See: https://creativecommons.org/licenses/by-nc-nd/4.0/.

\section{References}

1. Gonfiotti A, Jaus MO, Barale D, et al. Carinal resection. Thorac Surg Clin 2014;24:477-84.

2. Macchiarini P, Altmayer M, Go T, et al. Technical innovations of carinal resection for nonsmall-cell lung cancer. Ann Thorac Surg 2006;82:1989-97; discussion 1997.

3. Porhanov VA, Poliakov IS, Selvaschuk AP, et al. Indications and results of sleeve carinal resection. Eur J Cardiothorac Surg 2002;22:685-94.

4. Mitchell JD, Mathisen DJ, Wright CD, et al. Resection for bronchogenic carcinoma involving the carina: long-term results and effect of nodal status on outcome. J Thorac Cardiovasc Surg 2001;121:465-71.

5. de Perrot M, Fadel E, Mercier O, et al. Long-term results after carinal resection for carcinoma: does the benefit warrant the risk? J Thorac Cardiovasc Surg 2006;131:81-9.

6. Regnard JF, Perrotin C, Giovannetti R, et al. Resection for tumors with carinal involvement: technical aspects, results, and prognostic factors. Ann Thorac Surg 2005;80:1841-6.

7. Yamamoto K, Miyamoto Y, Ohsumi A, et al. Surgical results of carinal reconstruction: an alterative technique for tumors involving the tracheal carina. Ann Thorac Surg 2007;84:216-20.

8. Costantino CL, Geller AD, Wright CD, et al. Carinal surgery: A single-institution experience spanning 2 decades. J Thorac Cardiovasc Surg 2019;157:20732083.e1.

9. Qiu T, Zhao Y, Song J, et al. Two-port approached thoracoscopic carina reconstruction using natural bronchial bifurcation. J Cardiothorac Surg 2016;11:147.

10. Nakanishi R, Yamashita T, Muranaka K, et al. Thoracoscopic carinal resection and reconstruction in a patient with mucoepidermoid carcinoma. J Thorac Cardiovasc Surg 2013;145:1134-5.

11. Li J, Wang W, Jiang L, et al. Video-Assisted Thoracic Surgery Resection and Reconstruction of Carina and Trachea for Malignant or Benign Disease in 12 Patients: Three Centers' Experience in China. Ann Thorac Surg 2016;102:295-303.

12. Jiang L, Liu J, Gonzalez-Rivas D, et al. Thoracoscopic surgery for tracheal and carinal resection and reconstruction under spontaneous ventilation. J Thorac Cardiovasc Surg 2018;155:2746-54.

13. Gonzalez-Rivas D, Paradela M, Fieira E, et al. Singleincision video-assisted thoracoscopic lobectomy: initial results. J Thorac Cardiovasc Surg 2012;143:745-7.

14. Gonzalez-Rivas D, Paradela M, Fernandez R, et al. 
Uniportal video-assisted thoracoscopic lobectomy: two years of experience. Ann Thorac Surg 2013;95:426-32.

15. Hernandez-Arenas LA, Purmessur RD, Gonzalez-Rivas D. Uniportal video-assisted thoracoscopic segmentectomy. J Thorac Dis 2018;10:S1205-14.

16. Gonzalez-Rivas D, Soultanis KM, Garcia A, et al. Uniportal video-assisted thoracoscopic lung sparing tracheo-bronchial and carinal sleeve resections. J Thorac Dis 2020;12:6198-209.

17. Hu D, Wang Z, Tantai J, et al. Robotic-assisted

Cite this article as: Matsuura N, Igai H, Kamiyoshihara M. Carinal resection and reconstruction: now and in the future. Transl Lung Cancer Res 2021;10(10):4039-4042. doi: 10.21037/ tlcr-21-731 thoracoscopic resection and reconstruction of the carina. Interact Cardiovasc Thorac Surg 2020;31:912-4.

18. Li S, Ai Q, Liang H, et al. Non-intubated Robotic-Assisted Thoracic Surgery for Tracheal/Airway Resection and Reconstruction: Technique Description and Preliminary Results. Ann Surg 2021. [Epub ahead of print]. doi: 10.1097/SLA.0000000000004887.

19. Melfi FM, Menconi GF, Mariani AM, et al. Early experience with robotic technology for thoracoscopic surgery. Eur J Cardiothorac Surg 2002;21:864-8. 